\title{
ACERCA DE ANTONIO SKÁRMETA
}

Casa América, en Madrid, le dedicó al escritor chileno Antonio Skármeta el ciclo "Semana del Autor" entre el 20 y el 25 de abril de 2009. En estas páginas se recogen los textos que los escritores y ensayistas Juan Villoro, Rodrigo Fresán y Niall Binns presentaron en esa ocasión. Los dos primeros durante la mesa redonda titulada "Desnudo en el Tejado: Los cuentos de Skármeta", que tuvo lugar el 20 de abril. El texto de Niall Binns corresponde a la presentación que abrió las jornadas sobre las novelas de Skármeta el 21 de abril.

Juan Villoro $\quad$ Elogio familiar de Antonio Skármeta ... 310

Rodrigo Fresán “A las Arenas” revisitado, o apuntes sobre la relectura de un cuento de Antonio Skármeta

Niall Binns Skármeta el novelista y la moneda cotidiana de la poesía

Palabras clave: literatura hispanoamericana; Antonio Skármeta. 


\section{ELOGIO FAMILIAR DE ANTONIO SKÁRMETA*}

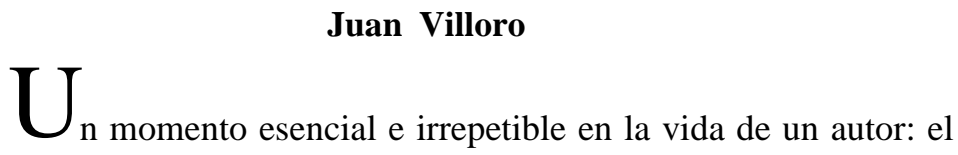
comienzo. No me refiero a los primeros escarceos, sino al comienzo absoluto, cuando aún no ha escrito nada y una pulsión lo lleva a marcar una hoja guiado por su voluntad. Con el tiempo, ese inicio adquiere rango mítico, el origen del que todo se desprende.

Nadie practica ese gesto sin recurrir a un modelo. La angustia de la influencia se muestra con más fuerza en los primeros textos. ¿Cómo encontrar un precedente? Ciertos autores cautivan pero son inimitables. A los 15 años, yo hubiera dado cualquier cosa por ser un novelista ruso, pero desde luego, eso escapaba a mis posibilidades.

El primer texto que escribí, a los 14 años, era una adaptación urbana de Juan Rulfo. Yo no bebía cerveza ni había entrado en un bar, pero mi primera frase literaria fue: "Cuatro cervezas sobre un paño verde, rasgado en el centro”. El cuento se llamaba "Los Hijos de Aída” y se ubicaba en una cantina con ese nombre (el propietario era fanático de esa ópera, que yo, por supuesto, no había escuchado). Le di el cuento a mi madre y se sorprendió con el escenario desastrado y esa historia de borrachos que querían poner una bomba. Aquel mundo

JuAn Villoro. Escritor mexicano. Nació en el Distrito Federal el 24 de septiembre de 1956. Autor, entre muchas otras obras, de los cuentos La Casa Pierde (1999, Premio Xavier Villaurrutia), El Mariscal de Campo (1978), La Noche Navegable (1980), El Cielo Inferior (1984); las novelas Llamadas de Amsterdam (2007) y El Testigo (Premio Herralde 2004); los ensayos De Eso Se Trata (2008), Efectos Personales (2000, Premio Mazatlán) y Los Once de la Tribu (1995); de las crónicas El Tiempo Transcurrido (1986) y los relatos infantiles Las Golosinas Secretas (1985) y Baterista Numeroso (1997). Ha colaborado en las revistas Cambio, Gaceta del Fondo de Cultura Económica, Universidad de México, Crisis, La Orquesta, La Palabra y el Hombre, Nexos, Vuelta, Siempre!, Proceso y Pauta, de la cual fue jefe de redacción, y del suplemento "Revista de Libros", de El Mercurio de Santiago. Fue agregado cultural en la embajada de México en Berlín (1981-1984) y director del suplemento La Jornada Semanal (1995 a 1998). En 1988 también fue distinguido con el Premio Cuauhtémoc de Traducción.

* Texto presentado el 20 de abril de 2009, en Madrid, durante la mesa redonda "Desnudo en el Tejado: Los cuentos de Skármeta" realizada en el marco del ciclo “Semana del Autor” que Casa América dedicó al escritor chileno Antonio Skármeta. La presentación fue leída por Renata Villoro, hermana del autor. 
patibulario la preocupó lo suficiente para pedir auxilio a su amiga Margo Glantz, conocida ensayista literaria. Ella se entusiasmó con lo que a mi madre le asustaba: “¡Tienes talento para la sordidez!”, exclamó. Luego me recomendó a Onetti.

Tomé un tranvía rumbo a la Librería Zaplana, ya desaparecida. Ahí encontré Contramutis, de Jorge Onetti. Era una novela complicadísima. La recomendación de Margo Glantz me desconcertó: eso no tenía nada que ver conmigo. Unos meses después supe que había leído al Onetti equivocado, el hombre al que Juan Cruz preguntó: “¿Por qué no firmas con tu segundo apellido?”, sólo para recibir esta demoledora respuesta: "Es que mi segundo apellido es Borges".

Finalmente di con una edición de El Astillero, prologada por José Donoso. El mundo de Juan Carlos Onetti fue para mí un milagro excesivo, como si recibiera en custodia un iceberg, el vértigo horizontal de la pampa o un millón de pájaros. Un regalo para un emperador chino. Yo no podía imitar esa intensidad ni asumir descalabros tan mayúsculos. Margo me había diagnosticado talento para la sordidez, pero a los 15 años estaba muy lejos de esa poética de la devastación.

Escribí sin rumbo algunos textos que acabaron en el basurero hasta que Miguel Donoso Pareja, mi maestro de taller de cuento, tuvo una inspiración. Nos reuníamos los miércoles, a las 7 de la noche, en el piso 10 de la Torre de Rectoría, en Ciudad Universitaria. Sesionábamos en las oficinas vacías de Difusión Cultural. Un solitario foco alumbraba el círculo de sillas. Al fondo, se veía la sombra del estadio de fútbol, como un escarabajo boca arriba. Ése fue el escenario de la epifanía.

Donoso Pareja era un hombre carismático. Había sido guerrillero maoísta en Ecuador, había estado en la cárcel, había trabajado en barcos mercantes. Tenía una barba al estilo Ho Chi Minh, que empujaba hacia delante mientras leía un texto. Con su voz curtida en la clandestinidad, los presidios y las sales marinas, leyó el cuento "El Ciclista del San Cristóbal”, de Antonio Skármeta. A mi lado estaba José Luis Zendejas, joven poeta radical que poco después escribiría con el nombre de guerra de Mario Santiago Papasquiaro y muchos años más tarde aparecería en la novela Los Detectives Salvajes con el nombre de Ulises Lima. En un momento de la lectura, se volvió a verme con ojos de lumbre. Gran crítico de narrativa, Mario sabía que esas palabras me convenían. El mundo de Skármeta era el mío, el mundo de las calles, las bicicletas, el rock, las pizzas, los locutores de la radio, las adorables 
chicas imposibles, pero tenía algo más: llegaba poetizado con un sentido lúdico. En ese territorio, las metáforas eran la forma natural de la expresión. El escritor chileno inventaba imágenes con la espontánea gracia con que un centro delantero inventa goles. En sus cuentos, el cielo valía la pena porque se llenaba de pájaros y la noche porque permitía delirar bajo la galaxia.

"El Ciclista del San Cristóbal” empezaba in media res, como si en rigor hubiera comenzado antes: "Además era el día de mi cumpleaños”. Tal era la primera frase. ¿Además de qué? ¡Además de todo! Nada podía captar lo que yo sentía como la palabra “además”. Además de todo tenía examen, además de todo Laura no me quería, además de todo el Necaxa no ganaba partidos, además era el día de mi cumpleaños.

El mundo editorial latinoamericano de los años setenta estaba mejor vinculado que el de ahora. En México, era posible conseguir libros de Argentina, Colombia, Cuba, Venezuela o Puerto Rico. En la Librería del Sótano encontré Desnudo en el Tejado, en la edición cubana de Casa de las Américas. Ese libro, que incluía "El Ciclista del San Cristóbal”, se convirtió en mi favorito, no sólo en términos de lectura, sino de imitación. Escribí con el frenesí de quien tiene a alguien que seguir. Pedaleaba en mi bicicleta detrás de un puntero con el suéter amarillo del que define la ruta.

Me costó un trabajo enorme conseguir El Entusiasmo, primer libro de cuentos de Skármeta, y un trabajo superior conseguir el tercero, Tiro Libre. La editorial Siglo XXI había publicado este título en Chile o Argentina, poco antes del golpe de Pinochet. Leí una reseña del escritor mexicano Héctor Manjarrez donde decía que temía por la vida del autor. No sé cómo consiguió ese ejemplar en un momento en que las obras de valía eran quemadas por los militares, con la apropiada confusión de los ignorantes, que condenaba a la hoguera un libro sobre cubismo, pensando que trataba de la Cuba castrista, y salvaba un título casto: La Sagrada Familia, de Marx y Engels.

Yo estudiaba el bachillerato en el Colegio Madrid, fundado por republicanos españoles. La tradición de asilo del colegio hizo que se diera acogida a los exiliados chilenos. La primera manifestación en la que participé fue en repudio al golpe de Estado en Chile. Cada generación tiene su Gran Canalla, su criminal histórico. La de mi padre tuvo a Franco, la mía a Pinochet. Chile se convirtió en un país esencial para 
nosotros. Nos enamoramos en bloque de las chilenas que llegaron al colegio y aprendimos canciones tristísimas sobre las minas de cobre. En medio de esta educación política y sentimental, yo buscaba el tercer libro de Skármeta con la obsesión de un fanático. Cada semana iba a las oficinas de Siglo XXI a ver si ya les había llegado un ejemplar. La secretaria me trataba con el respeto que merece un perturbado. Fue tal mi insistencia que un día me hablaron por teléfono. Es la única vez que una editorial me ha anunciado la aparición de un libro: Tiro Libre había dado en el blanco.

Leí con emoción los cuentos ubicados en el Chile de la Unidad Popular, la utopía que acababa de ser aniquilada. En ese momento surgió en mi escuela la idea de hacer una revista. Naturalmente, decidimos dedicar el primer número a Chile. Yo escribí un texto delirante en el que hablaba, simultáneamente, de los cuentos de Skármeta y de un libro de autoayuda marxista: Los Conceptos Elementales del Materialismo Histórico, escrito por su paisana Marta Harnecker.

Entregamos los originales al editor, Manuel Ulacia, nieto del poeta español Manuel Altolaguirre, y él los guardó en el maletero de su coche. La inclemente diosa Fortuna hizo que esa misma tarde le robaran el coche. Las obras completas de una generación desaparecieron ahí. Mi primer texto crítico y los de mis compañeros se esfumaron para siempre. Nadie había tomado la precaución de sacar fotocopias o hacer copias al carbón.

Poco después, Skármeta publicó su primera novela, Soñé que la Nieve Ardía. Ahí, el golpe de Estado es visto por un joven centro delantero. De nuevo, el narrador mezclaba un momento histórico decisivo con los días sin brújula de la adolescencia. La lección de Skármeta consistía en darle centralidad al universo juvenil y lograr que los ritos de iniciación de la contracultura se inscribieran en una historia que los rebasaba y trascendía.

Skármeta era un puente perfecto entre la literatura de umbral, entre lo real y lo fantástico, de Cortázar, Onetti, Borges y Bioy Casares, y el mundo pop, determinado por impulsos juveniles, de Jack Kerouac y J. D. Salinger. Muchos de sus cuentos ocurrían “en el camino” y no es casual que impactaran a Roberto Bolaño.

En 1976 participé en el concurso de la revista Punto de Partida y obtuve el segundo lugar en cuento. En ese mismo certamen, Roberto obtuvo el tercer lugar en poesía. Uno de los jurados de cuento era el 
escritor chileno Poli Délano, exiliado en México. Naturalmente, detectó la influencia de Skármeta en mi escritura y empezamos a hablar de él. Bolaño se acercó y dijo que esos cuentos eran tan potentes como la gran narrativa rusa. Ahí se inició nuestra amistad y alguna vez, en la imprescindible compañía de Rodrigo Fresán, comentamos el relato “A las Arenas”, de Skármeta, donde dos jóvenes, un chileno y un mexicano, que han peregrinado en autopista a Nueva York, se enteran de que hay un estupendo concierto de jazz, pero no tienen dinero para asistir. Deciden entonces vender su sangre para pagar las entradas. ¿Cómo llamarles a quienes están dispuestos a cambiar su sangre por el arte? Bolaño encontraría una expresión indeleble años después: “detectives salvajes”, y escribiría la saga del chileno Arturo Belano y el mexicano Ulises Lima. Ese impulso de entender la vida como obra de arte y de investigarla de modo rebelde provenía de Kerouac y, más cerca de nosotros, de Skármeta.

Las influencias son como llamaradas que alumbran a cierta distancia y calcinan en excesiva cercanía. Leí a Skármeta con fervor imitativo hasta que encontré otros rumbos y él mismo transitó hacia otros territorios narrativos.

En 1980 llegué a vivir a Berlín oriental. Sabía que al otro lado del Muro vivía Skármeta, pero el pudor y la admiración me impidieron buscarlo. Un día, él habló a la embajada de México, donde yo trabajaba. Necesitaba una visa para ir a un encuentro literario.

Había leído los cuentos de Skármeta las mismas veces que había escuchado "Stairway to Heaven", de Led Zeppelin. Esto me llevó a ser bastante tímido en nuestro primer encuentro. Me limité a mencionar sus relatos en tono reverente y dije alguna bobada. Pensé que el trato terminaría ahí, pero Antonio decidió adoptarme. Poco después me invitó a cenar. Yo estaba tan nervioso que perdí mi cartera, donde lo único valioso era mi credencial del Partido Mexicano de los Trabajadores. Era el miembro 879. “¡Me encantaría ser miembro de un partido político con menos de mil militantes!”, dijo Skármeta. Salimos a las calles de la ciudad dividida y ahí comenzó otra travesía, la de una amistad que desembocaría en el milagro de la hermandad.

Cuando conocí al escritor húngaro Peter Esterhazy, reparamos en que ambos éramos primogénitos. Dos ilusiones habían marcado nuestra infancia de idéntica manera: tener un hermano mayor y tener 
un teléfono. Crecer significaba conseguir la segunda (y descubrir que era una lata) y resignarse a no conseguir la primera.

Pero a veces la literatura ofrece raras compensaciones: esta noche mi hermana menor ha leído este texto sobre mi hermano mayor, de legendario origen yugoslavo, nacido en el desierto de Antofagasta, que llenó el cielo de pájaros y mostró que un joven ciclista solitario podía medir con sus pies el tamaño del mundo y la deriva de las galaxias. 


\section{“A LAS ARENAS” REVISITADO, O APUNTES SOBRE LA RELECTURA DE UN CUENTO DE ANTONIO SKÁRMETA*}

\section{Rodrigo Fresán}

UNO. Siempre me gustó pensar en el lector —en las diferentes edades del lector - como en uno de esos gráficos de enciclopedia que muestran al hombre alzándose desde los abismos del simio, pasando por diferentes esqueletos y posturas, hasta alcanzar la altura vertical e intelectual del homo sapiens y aquí estamos.

Y, para mí, la posición más noble y final, la postura definitiva, sería la de contemplar a ese animal — que alguna vez se arrastró fuera de las aguas y trepó a los árboles — sentado y sosteniendo un libro en esas manos que alguna vez fueron garras.

Me explico: cuando uno empieza a leer, primero se preocupa por el héroe, luego por la trama, más tarde por el autor que creó a ese héroe y a esa trama (y por la posibilidad de que existan otros libros suyos por leer) y, al final, se accede a la preocupación más exquisita de todos y a la que no muchos llegan porque, sencillamente, no les interesa demasiado pensar en esas cosas.

Me refiero aquí a la muy feliz y nutricia preocupación por el estilo.

Y el estilo es el idioma de un escrito.

DOS. Enumero todo esto porque me interesa precisar qué tipo de lector era yo cuando me crucé por primera vez con un relato de Antonio Skármeta titulado “A las Arenas” e incluido en un libro llamado Desnudo en el Tejado.

RODRIGO Fresán. Escritor y periodista argentino, nació en Buenos Aires en 1963. Su primera obra, Historia Argentina (1991), un libro de cuentos, fue elegida por la crítica como la revelación narrativa de 1991. Un segundo libro de relatos, Vidas de Santos (1993), precedió a sus novelas Trabajos Manuales (1994) y Esperanto (1995). En 1999 se trasladó a Barcelona, donde ha publicado las novelas Mantra (2001) y Jardines de Kensington (Premio Lateral de Narrativa Extranjera, 2003), El Fondo del Ciclo (Mondadori, 2009), además de versiones corregidas y aumentadas de algunos de sus libros anteriores.

* Texto presentado el 20 de abril de 2009, en Madrid, durante la mesa redonda "Desnudo en el Tejado: Los cuentos de Skármeta" realizada en el marco de la "Semana del Autor” que Casa América consagró al escritor chileno Antonio Skármeta. 
No recuerdo dónde estaba yo exactamente (en algún lugar de Buenos Aires, frente a los estantes de alguna biblioteca o librería, seguro) pero sí recuerdo cómo estaba yo.

Yo, por entonces, debía tener unos catorce o quince o dieciséis años (tres años que, se sabe, forman parte de un mismo año porque, de los catorce a los dieciséis se tiene una misma edad y el tiempo parece transcurrir tres veces más despacio de lo que transcurre para los que tienen trece o diecisiete).

Yo, sí, ya quería ser escritor y venía queriéndolo ser desde hace tanto tiempo que probablemente ya lo fuera.

Quedaba, claro, solucionar ese pequeño detalle técnico de primero terminar un libro y verlo publicado después; pero lo cierto es que mi vocación había sido debidamente comunicada a mis padres ya con un lustro de edad y, desde entonces, escribía cuentos y primeros capítulos de novelas que — suele suceder — nunca alcanzaban el capítulo dos.

O el tres.

Los capítulos propios, como los años, también transcurrían mucho más lento.

Es por eso que es a esa edad cuando, como reacción a todo eso, uno lee más rápido y mejor que nunca.

TRES. Y once años después de saber lo que quería ser cuando fuera grande, a los catorcequincedieciséis años, yo estaba en problemas.

Mi madre, que era muy inteligente y muy lectora, me miraba con cara de cuándo-va-a-salir-tu-libro.

En cambio a mi padre, que también era muy inteligente, no lo le gustaba mucho leer por más que hubiera hecho libros sobre Jorge Luis Borges y Julio Cortázar. Mi padre — deformaciones de su oficio— era un muy reconocido diseñador gráfico que no tenía problema alguno en afirmar que "todos los libros son iguales: marcas negras sobre fondo blanco”. Por eso mi padre prefería los ensayos y, cuando se trataba de ficciones, defendía a muerte la practicidad minimal de los microrrelatos. $Y$, no sé cómo (su otra gran idea era que yo escribiera todo un libro de relatos que tuvieran como tema a la Coca-Cola porque "todo el mundo bebe Coca-Cola”) mi padre se las había arreglado para convencerme de que mi genio pasaba por esa variedad de los cuentos. 
Y así — como si yo fuera un bonsái o un pie de geisha— yo sólo escribía ficciones súbitas.

Y, para colmo, todas esas ficciones súbitas transcurrían lejos de Argentina y desbordaban de nombres ingleses, nacionalidad de mis autores y libros favoritos.

Y un editor había espiado esas páginas y me había dicho: "No están mal. Pero parecen cuentos doblados al español en Puerto Rico".

Lo que me lleva de regreso a "A las Arenas" y a Desnudo en el Tejado.

Vi ese libro y me gustó ese título.

Comprobé que había sido originalmente publicado en 1969 y obsesión recurrente por entonces: saber a qué edad habían publicado los otros. Lo que convertía a Antonio Skármeta (nacido en Chile en 1940) en un joven de veintinueve años para la fecha en que Desnudo en el Tejado había llegado a librerías.

La noticia biblio-biográfica del libro me informaba también, atención, que había otro libro —un título anterior — de Skármeta: El Entusiasmo, de 1967.

Lo que todavía me daba cierto tiempo.

Decidí de inmediato que Skármeta me caía bien porque —hasta donde yo sabía y a diferencia de Truman Capote — no había publicado nada a los dieciocho años.

Y volviendo a lo del principio: yo tenía dieciséis años (o quince, o catorce) pero ya me preocupaba el estilo, el idioma.

Yo acaba de ser azotado por el gozoso huracán de En el Camino de Jack Kerouac, que no tenía nada que ver con el estilo de las plácidas y flemáticas brisas de Aldous Huxley, a quien tanto había leído y a quien tanto quería parecerme entonces.

Y, claro, entre uno y otro, Salinger y Fitzgerald y Cortázar y los cuentos fantásticos de Adolfo Bioy Casares y la música y el cine y, sí, esa edad en que nuestra cabeza parece preparada para asimilarlo y comprenderlo todo al mismo tiempo. Esa edad en la que sitio libre es lo que sobra dentro nuestro, porque afuera hay tantos sitios a los que ir por primera vez como si fuera la última vez, hay tantos tejados y uno se siente tan desnudo que no para de vestirse, de cubrirse el cuerpo con capas de información, de ropas cortadas por los que alguna vez estuvieron desnudos como nosotros pero ya no.

$\mathrm{Y}$ entonces nos ofrecen los abrigos que cosieron para abrigarse ellos pensando que, tal vez, también nos vayan bien a nosotros. 
Y se sabe: pocas cosas calientan más y mejor que un buen cuento.

Así que abrí el ejemplar de Desnudo en el Tejado con cierta curiosidad malsana: ahí había un escritor joven (veintisiete años, edad a la que finalmente yo publicaría mi primer libro), cercano geográficamente (chileno), autor de un libro breve en páginas (lo que siempre llenaba de esperanzas) y con un título tan intrigante.

Título que, saltando al índice, era el de uno de los relatos allí contenidos.

El último de todos.

Y era un microrrelato.

Y decía así:

“¿Y qué pretendes? ¿Qué viva desnudo en el tejado?”.

Recuerdo haber leído esas dos líneas y reírme y no entender muy bien de qué me estaba riendo.

Porque "Desnudo en el tejado" era un microrrelato que parecía ser otra cosa.

Una parte de algo.

Una esquirla de una explosión más o menos cercana.

Poco y nada que ver con los microrrelatos que por entonces escribía yo.

CUATRO. Súbita y breve interferencia más que personal: el microrrelato favorito entre los míos se titulaba “Amnesia”.

Y decía así:

"En un lugar de La Mancha de cuyo nombre no puedo acordarme".

Y punto final.

$\mathrm{Y}$ fin de la interferencia.

CINCO. Y allí estaba yo otra vez hojeando el libro de Skármeta.

Creo que leí de pie —uno siempre se recuerda leyendo de pie aquello que le resultó importante- el cuento titulado "El Ciclista del San Cristóbal” y, sí, comencé a sentir cierta incomodidad.

Porque ahí estaba un chileno -ahí estaban los nombres, la lingua chilensis - pero ahí también estaban, para mí, el formato de los relatos norteamericanos que entonces yo más que leer estudiaba (Hemingway, Fitzgerald, Salinger); la graciosa buena idea de fonetizar el inglés para 
así acentuar el extravío del que se sabe extranjero para siempre; un envidiable manejo del diálogo (mi punto débil entonces y mi agujero negro ahora); y la tan envidiable y vertiginosa velocidad beatnik.

Ahí estaba, en resumen, todo lo que yo quería hacer, y no sabía cómo hacer, hecho por un chileno.

Y, para colmo, además, los chilenos no sólo tenían a Skármeta sino, también, ese santuario alien conocido como la Isla de Pascua. Y tenían al Dr. Mortis. Es verdad, también tenían cosas insufribles como Condorito. Pero por encima de todo y todos lo tenían a Skármeta que escribía un microrrelato raro y, además, "El Ciclista del San Cristóbal”.

Poco y nada me importaba el conflictivo Canal del Beagle.

A mí me importaba Skármeta y recuerdo que la primera vez que llegué a Santiago lo primero que pregunté fue “¿Dónde está el cerro San Cristóbal?”.

$\mathrm{Y}$, al pasar al segundo relato, a “A las Arenas”, la cosa se complicó todavía más.

Se complicó para bien, para mejor, para mucho mejor todavía.

SEIS. Casi treinta años después sigo hablando de ese relato.

Se lo recomiendo a conocidos y desconocidos.

Siempre igual: condenso su argumento, lo vuelvo, sí, casi un microrrelato y después me río.

Digo: "Es la historia de dos amigos o conocidos —un mexicano de nombre mutante y un chileno- que, muertos de hambre en Nueva York, venden sangre por unos dólares y, exhaustos, acaban gastándose ese dinero invitando a un par de chicas a un concierto de Ella Fitzgerald".

Así lo contaba yo siempre.

Así lo contaba yo amparado en un recuerdo inolvidable.

En “A las Arenas" yo conocí en la lectura y reconocí en la relectura, por encima de todo, un ritmo, una determinada respiración, el latido exacto y sin intermitencias que, muy de tanto en tanto, escuchamos en un cuento y que nos permite decirnos que esa historia no se puede contar de otra manera.

Las tramas de novelas permiten, casi siempre, miradas alternativas y modificaciones en el punto de vista y, claro, imperfecciones.

El cuento como género, en cambio, es el más demandante de los patrones. 
Allí no hay segundas oportunidades ni sitio para disculpas.

Allí se trata de sentirse satisfecho y de satisfacer.

En el cuento no se puede andar con cuentos porque, seguro, te caes.

Y, sí, el estilo, el tener estilo...

Vuelvo a él y "A las Arenas” para escribir estas líneas y su efecto se mantiene y la admiración aumenta.

Y ahí está esa enfermera filósofa extrayendo sangre e inyectando un sabio "Así es nuestra vida, puras burbujas. Viene un aire un día y se las lleva”.

Y ese "Ahí sí que hicimos el amor. Primero moviéndonos casi imperceptibles, como intercambiándonos regalos de Navidad”.

Y ahí están, mencionados, Borges y Saroyan, Gregory Peck y Audrey Hepburn y "King of the Road”.

Y ese crepuscular amanecer del final y de dónde había salido Skármeta volví a decirme, otra vez, por más que yo ya conociera a Skármeta, por más que — con los años — me hubiera cruzado un par de veces con él y lo disfrutara en un programa de televisión donde, siempre, tenía el raro e inmenso detalle de presentarse como lector entusiasta y no como un escritor broncíneo.

Podría, claro, ensayar aquí argumentos críticos/geográficos/ cronológicos; decir que Skármeta es una especie de Big Bang; que Skármeta anticipa las explosiones de otros chilenos "raros" como Roberto Bolaño o Alberto Fuguet.

Y hasta podría asegurar que en otra dimensión "A las Arenas" - y no Stranger Than Paradise - es el título de la primera película de Jim Jarmusch.

Pero no.

Estoy seguro que otros participantes de esta mesa redonda (que es rectangular como suelen serlo las mesas redondas) están mejor calificados para eso.

Prefiero, en cambio, recordar — sentado aquí, junto a Skármeta, vestido en este subsuelo de la Casa América de Madrid— a aquel que era yo cuando leyó por primera vez "A las Arenas".

Me parece más justo, más honesto, más apropiado para esta noche.

Porque para mí “A las Arenas" —el efecto se repetiría igual de intenso, pero ya asumida la normalidad de la rareza de otros relatos 
como "La Cenicienta en San Francisco", en otras tejas y aleros de Desnudo en el Tejado- significó en su momento un mapa, una dirección, un camino a seguir, una palmada en la espalda de un gran amigo desconocido a quien hoy, por suerte, conozco y reconozco.

Esa y ésta es, pienso, la tarea de los escritores que subieron primero al tejado, o dieron sangre antes que nosotros, o pedalean más adelante que uno: obligarnos a alcanzarlos.

Y, una vez alcanzados — sin que esto signifique, se entiende, ganarles o superarlos o dejarlos atrás; porque esos escritores siempre estuvieron y están y estarán junto a uno, advirtiéndonos de paisajes inolvidables y curvas peligrosas que ellos ya recorrieron - gritarles “iGracias!”.

Agradecerles con esa felicidad con que uno grita de una bicicleta a otra o de un tejado a otro, mientras el camino y el tiempo pasan y pasamos nosotros.

Los libros, los buenos libros de los buenos escritores, permanecen.

Y su generosa y vigorizante sangre no se agota nunca.

Escribo esto y, sí, necesito una transfusión, vuelvo a leer "A las Arenas”.

No va a ser la última vez que lo haga, seguro. 
SKÁRMETA EL NOVELISTA Y LA MONEDA COTIDIANA DE LA POESÍA

\section{Niall Binns}

Saltar de género — del cuento a la novela — en la lectura de Antonio Skármeta significa también, necesariamente, un salto en el tiempo. La evidencia es inapelable. Los tres primeros libros del autor eran colecciones de relatos -El Entusiasmo, de 1967; Desnudo en el Tejado, de 1969; Tiro Libre, de 1974—; a partir de entonces, los ocho libros que ha publicado son todos novelas. Se diría que es la historia de siempre: el aprendiz de narrador que da sus primeros pinitos en el género menor antes de atreverse con la novela; se diría eso, en todo caso, si no fuese porque aquellos primeros libros confirmaron a Skármeta como un maestro del relato, si no fuese por el puñado de cuentos dispersos que ha seguido escribiendo y que andan aún en busca de un libro, si no fuese porque esa historia de siempre —que sigue siéndolo casi siempre aquí en España- dejó de serlo hace mucho, ya se sabe, después de Quiroga y Borges y Arreola y Cortázar y Monterroso y tantos más.

La primera de las novelas de Antonio Skármeta, Soñé que la Nieve Ardía, es de 1975, y retrata las vivencias de un grupo de jóvenes que viven en la pensión santiaguina de Don Manuel durante los últimos meses de la Unidad Popular, y sobre todo las vivencias de Arturo, un genial pero egoísta jugador de fútbol, recién llegado del Sur, que se interesa más por su carrera como deportista y por la complicada pérdi-

Niall BinNs. Poeta, traductor y ensayista. Hijo de padres escoceses, nació en Londres en 1965. Luego de graduarse en lenguas clásicas en Oxford vivió en Francia, Portugal y Chile. Ha publicado dos libros de poesía: Tratado sobre los Buitres (2002) y Canciones Bajo el Muérdago (2003). Ha colaborado en diversos proyectos musicales y publicado varios libros de ensayo literario; entre ellos, Un Vals en un Montón de Escombros (1999), Nicanor Parra (2000), y La Poesía de Jorge Teillier: La Tragedia de los Lares (2001). Asimismo, ha sido editor literario, antólogo o traductor de libros de Nicanor Parra, Jorge Teillier y Dylan Thomas. Actualmente reside en España y es profesor de la Facultad de Filología en la Universidad Complutense de Madrid, donde dicta clases de literatura hispanoamericana, dirige talleres de poesía e investiga sobre la guerra civil española.

* Versión revisada de la presentación que Niall Binns hizo, como moderador, al inicio de las jornadas sobre la narrativa de Antonio Skármeta en el marco de la "Semana del Autor” que Casa América, en Madrid, le dedicó al autor chileno entre el 20 y el 25 de abril de 2009. 
da de su virginidad que por el inminente golpe de Estado de Augusto Pinochet, que terminará diezmando las esperanzas y las vidas de sus compañeros de pensión.

No pasó nada, de 1980, es una novela breve centrada en las experiencias de Lucho, el hijo adolescente de una familia chilena exiliada en Berlín, que lucha por crecer, integrarse y amar en una cultura y una lengua ajenas; una cultura y una lengua en principio, aunque cada vez menos, hostiles.

La Insurrección, de 1982, se centra en la lucha de guerrilleros y estudiantes nicaragüenses durante la Revolución Sandinista. Entre ellos está el Guatón Osorio, sobreviviente de la pensión de Don Manuel en Soñé que la Nieve Ardía, pero sobre todo el poeta guerrillero Leonel y su amada Vicky, que sufre la muerte de su hermano Agustín y padece ella misma la violencia de los somocistas antes de la llegada del triunfo final y el reencuentro amoroso con el novio.

Ardiente Paciencia, publicada en 1985 y hoy conocida mundialmente como El Cartero, relata la memorable relación de amistad entre el cartero Mario Jiménez y Pablo Neruda, así como su no menos memorable conquista de la bella Beatriz González y la breve convivencia conyugal de los dos en Isla Negra, antes de la llegada, la llegada inevitable y funesta, del golpe de Estado.

Matchball, de 1989, es otra novela que ha sido rebautizada $a$ posteriori, esta vez como La Velocidad del Amor. Skármeta se aleja aquí del contexto latinoamericano y retrata ahora, en una especie de fábula de nuestros perversos tiempos postmodernos, la historia del amor entre un médico cincuentón, el norteamericano residente en Alemania Raymond Papst, y una lolita fin-de-siglo, la tenista quinceañera Sophie Mass, una estrella de masas en la línea de la bella Steffi Graf, que en aquellos años dominaba el circuito del tenis femenino mundial.

En 1999 y 2001, Skármeta publica La Boda del Poeta y su continuación, La Chica del Trombón. La primera de estas novelas se sitúa a comienzos del siglo XX en una isla del Adriático, y explora el triángulo amoroso entre el banquero austriaco Jerónimo Frank, su joven y hermosa novia Alia Emar y el enamorado de ésta, Esteban Coppeta. La segunda de las novelas comienza décadas después, cuando el mismo Esteban Coppeta, hace mucho tiempo emigrado a Chile, recibe de manos de un trombonista una niña de dos años, supuestamente su nieta, que crecerá con él y aceptará el nombre y la identidad de su probable abuela, esa Alia Emar de comienzos del siglo. 
La última novela de Antonio Skármeta, El Baile de la Victoria, ganó el Premio Planeta de 2003. Habla del Gran Golpe preparado por el joven Ángel Santiago y el legendario ladrón Vergara Grey, ambos recientemente liberados de la cárcel por una amnistía, junto con la bella bailarina Victoria.

En la noche inicial de la Semana del Autor se habló del cambio de voz que aportaron los cuentos de Skármeta a la grisura —una grisura, hay que decirlo, a veces poderosa en su expresividad- que predominaba en los años sesenta en la narrativa chilena. Esos primeros libros de relatos estaban impregnados de una vitalidad y un entusiasmo juveniles — capaces de seducir en Buenos Aires a Rodrigo Fresán, en la Ciudad de México a Juan Villoro-, una vitalidad y un entusiasmo que nunca ha perdido Skármeta en sus novelas.

Hay que recordarlo. Llegar a la juventud en los años sesenta abría perspectivas vitales que habrían sido inconcebibles para autores de otras generaciones. Los jóvenes de la generación suya, como el propio Skármeta ha dicho, fueron los primeros en enfrentarse "masivamente con la elocuencia de los medios de comunicación de masas", con el cine en color, con la música rock y el folklore que convivían en sus tocadiscos; con la televisión —que llegó de verdad durante los mundiales de fútbol, celebrados en Chile en 1962—; con la producción masiva y el costo cada vez más barato, más accesible, de las motos y los coches; con la grabadora y la fotocopiadora; con la píldora anticonceptiva y con la droga. Era la década pop, la década de la contracultura, del hedonismo, del juego, de la libertad y la promiscuidad, la década hippy, la década de Vietnam, de Woodstock, de Make love not war, y la década también de la muy juvenil revolución cubana y las oleadas de euforia utópica y esperanzas de cambio que desencadenó en toda América Latina y de manera intensísima en Chile.

En este contexto, ¿cómo no podían sentir recelos Skármeta y otros narradores de su generación — sin ir más lejos, Mempo Giardinelli- ante la solemnidad, el monumentalismo y las pretensiones fundacionales y omniabarcadoras de los escritores del boom? De ahí esa "promiscuidad” estilística de la que habla el autor: su fusión de la gran tradición literaria — Shakespeare, Darío, Neruda - con el cine de Hollywood, los Beatles, los boleros y las telenovelas mexicanas. Adiós a ese abismo que dividía la "alta” cultura de la cultura "de masas”. No 
podría ser más significativo, en este sentido, el trabajo de Skármeta en el cine —ahí está, como hermana mayor de "Il Postino" de Michael Radford, su propia versión cinematográfica de la novela Ardiente Paciencia-, y en la televisión. Recuerdo el impacto que tuvo, durante los años que viví en Santiago, "El Show de los Libros", cuyo dinamismo y frescura, cuyo espíritu a la vez de juego y seriedad, cuya imbricación de la imagen visual con la palabra escrita fueron la prueba de algo que aquí, en España, parecería sencillamente imposible. Vale la pena recordarlo: un programa de libros no tiene por qué ser aburrido; otra conclusión viene a cuento: lo contrario del aburrimiento no es la frivolidad.

Hay dos cosas que quisiera comentar, antes de terminar, de esta promiscuidad o fusión de la "alta" y "baja" cultura, que comparte gozosamente el autor Antonio Skármeta con los personajes de sus novelas. Por una parte, ese rechazo a cualquier sacralización de la cultura, al elitismo de una escritura hecha para media docena de elegidos; y al mismo tiempo, ligado a este espíritu lúdico y desacralizador, el humor que recogen sus novelas, la desafiante insistencia en no tomar las cosas o, sobre todo, en no tomarse uno mismo demasiado en serio, la conciencia, quizá — como ha dicho uno de los poetas más queridos por Skármeta, Nicanor Parra—, de que "la verdadera seriedad es cómica”. Ahí están las alusiones constantes al antipoeta Parra en El Baile de la Victoria, o las palabras de Neruda al cartero Mario Jiménez, tremendas en su desolado humorismo, en las últimas páginas de Ardiente Paciencia: "Yo ya no necesito médico, hijo", le dice el poeta: "Sería mejor que me mandaran directamente al sepulturero". Y cuando Mario le pregunta cómo se siente, Neruda contesta: "Moribundo. Aparte de eso, nada grave”; o bien, citando a Shakespeare: “Te contestaré como Mercurio cuando lo ensarta la espada de Tibaldo. 'La herida no es tan honda como un pozo, ni tan ancha como la puerta de una iglesia, pero alcanza. Pregunta por mí mañana y verás qué tieso estoy’”. Hace cinco años, en una entrevista que le hizo Rafael Gumucio titulada "Soy un chico pop”, Skármeta recordaba estas palabras de Mercurio, citadas en la novela por su personaje Neruda, y afirmaba que en ellas "está toda mi literatura. Alguien, frente a su muerte, antepone ironía, metáfora, lenguaje. Su dignidad está en esa capacidad para poner el ingenio y el genio por delante del dolor".

La poesía es una presencia y una influencia intensa, constante, en la obra de Antonio Skármeta. Para él, se diría, al igual que para su 
compatriota Jorge Teillier, "la poesía debe ser una moneda cotidiana / debe estar sobre todas las mesas / como el canto de la jarra de vino que ilumina los caminos del domingo". Y lo es, para Skármeta y para los personajes de sus novelas: una presencia tan natural, central y cotidiana como la de la música y las películas. Lo cierto es, de todos modos, que en este mundo suyo, que es el mundo de los marineros que besan y se van, del cuerpo de mujer, blancas colinas, muslos blancos, de los astros que tiritan, azules a lo lejos, de Mujer, el mundo está amueblado por tus ojos, de los “Sonetos de la Muerte” y del "Hombre Imaginario", de te quiero, qué comienzo, peor es tragar saliva, del cuerpo que se enciende —en la secreta casa de la noche- como un árbol de pascua para una fiesta de ángeles perdidos; en este mundo de Skármeta, no hay amor sin poesía, ni poesía sin amor. Leonel y Victoria, los amantes de La Insurrección, hablan en sus cartas de Ernesto Cardenal, y transcriben en ellas versos de Rubén Darío, Javier Heraud y Gioconda Belli. En Matchball, Pablo Braganza —el joven rival español del médico Raymond Papst- embelesa a Sophie Mass leyéndole poemas de Bécquer, mientras que el hasta entonces cínico Papst, que se ha reído de semejante cursilería, también se emociona cuando recibe de Sophie un poema de Milosz, que es, para él, "una gota de sangre real entre los montones de fichas clínicas de vidas monótonas como la mía”.

Pero es, sobre todo, la poesía de Neruda, la contagiosa, seductora, popularísima y “casamentera” poesía de amor de Neruda, la que volverá una y otra vez como protagonista de las novelas de Skármeta. En Soñé que la Nieve Ardía, siguiendo los consejos poéticos de Don Manuel, el joven Arturo intenta infructuosamente seducir a su amiga Susana leyéndole versos de Neruda mientras "como una rama tentacular [...] fue metiéndole la mano en el escote hasta tocar por primera vez la piel elástica y formidable del pecho de la chica”. Y en No Pasó Nada, Lucho conquista a la joven alemana Edith metiendo en su bolso una traducción que le ha hecho de uno de los Veinte Poemas. Y por último, allí están las estrategias de seducción de Mario Jiménez, que encandila a Beatriz González con la poesía que ha plagiado de Neruda. “iCon las metáforas, pues Don Pablo” — dirá la iracunda madre de la muchacha al poeta-, "tiene a mi hija más caliente que una termita!”. En definitiva, "prefier[e] mil veces que un borracho [l]e toque el culo [a Beatriz] 
en el bar, a que [1]e digan que una sonrisa [s]uya vuela más alto que una mariposa”...

En fin: en las novelas de Antonio Skármeta está siempre el amor, siempre la poesía, y siempre ese regalo de ternura y tristeza, juego e invención, sufrimiento, sensualidad, erotismo y alegría, que hace de su narrativa un festín literario tan sumamente entrañable. No quisiera terminar, por otra parte, sin decir que tampoco he visto, o muy pocas veces he visto, una atmósfera literaria tan entrañable como en los coloquios y las sobremesas de la Semana del Autor dedicada a Skármeta. 